\title{
A +2138InsCAGACC Polymorphism of the Melanocortin Receptor 3 Gene is Associated in Human with Fat Level and Partitioning in Interaction with Body Corpulence
}

\author{
N. Boucher, ${ }^{1}$ C.M. Lanouette,${ }^{1}$ M. Larose $^{1}{ }^{1}$ L. Pérusse, ${ }^{1}$ C. Bouchard ${ }^{2}$ and Y.C. Chagnon ${ }^{1,3}$ \\ ${ }^{1}$ Laval Hospital Research Center and Kinesiology, Department of Social and Preventive Medicine, Faculty of \\ Medicine, Laval University, Ste-Foy (Qc), Canada \\ ${ }^{2}$ Pennington Research Center, Louisiana State University, Baton-Rouge, LA, USA \\ ${ }^{3}$ Actual address: Laval University Research Center Robert-Giffard, Beauport (Qc), Canada \\ Accepted March 11, 2002
}

\begin{abstract}
Background: The melanocortin system includes five receptors (MC1R to MC5R), and mouse and human MC4R has been shown to be involved in the regulation of feeding, and mouse MC3R in body composition. To verify a possible similar effect of MC3R in humans, we analyzed one insertion and one single nucleotide polymorphism by restriction fragment length polymorphisms (RFLP), and a microsatellite (D20S32e) in relation to body composition and glucose metabolism.

Methods: Eight hundred twelve subjects of the Québec Family Study (QFS) cohort were analyzed for body composition, food intake, and energy metabolism phenotypes. Southern Blot with the complete MC3R cDNA was used to detect a new +2138InsCAGACC variant by Pst 1 restriction. PCR-RFLP with BsaJl was used to type amino acid polymorphism V81I arising from a G241A nucleotide change. PCR and automatic DNA sequencers were used for the analysis of the TG dinucleotide repeat D20S32e located between -1933/-1892 of MC3R. In a covariance analysis among genotypes, phenotypes were adjusted for age and sex as covariates. Food intake and energy metabolism phenotypes were also adjusted for body mass index (BMI), and leptin and abdominal fat, as assessed by a computed tomography scan, for fatness using six skinfold thicknesses.
\end{abstract}

Results: An association between the +2138 InsCAGACC MC3R polymorphism was observed with fat mass (FM), percent body fat (\%FAT), and total abdominal fat (ATF). Homozygote subjects for the +2138 insertion variant allele in normal weight $\left(\mathrm{BMI}<25 \mathrm{~kg} / \mathrm{m}^{2}\right)$ and overweight $(25 \leq$ $\mathrm{BMI}<30 \mathrm{~kg} / \mathrm{m}^{2}$ ) subjects showed a similar level of fatness despite the overall difference in BMI. In normal weight, homozygotes for the insertion allele showed higher mean values than heterozygotes and homozygotes for wild-type allele without insertion (\%FAT: $24.0 \pm 1.1$ versus $19.3 \pm 0.9$ and $20.5 \pm 0.8, p=0.0005 ; \mathrm{FM}: 15.7 \pm 0.9 \mathrm{~kg}$ versus $11.7 \pm$ $0.7 \mathrm{~kg}$ and $12.6 \pm 0.6 \mathrm{~kg}, p=0.0003)$. In contrast, overweight subjects homozygote for the variant allele showed lower mean values (\%FAT: $27.0 \pm 1.2$ versus $31.4 \pm 0.8$ and $30.9 \pm 0.7, p=0.002 ; \mathrm{FM}: 18.3 \pm 1.0 \mathrm{~kg}$ versus $22.8 \pm 0.8 \mathrm{~kg}$ and $22.0 \pm 0.6 \mathrm{~kg}, p=0.0001$ ). This resulted in a similar level of body fat between both BMI groups for subjects homozygote for the insertion allele versus wild-type allele carriers (\%FAT: $\pm 2-3 \%$ versus $\pm 10-12 \%$; FM: $\pm 2 \mathrm{~kg}$ versus $\pm 9-11 \mathrm{~kg})$. In obese subjects $\left(\mathrm{BMI} \geq 30 \mathrm{~kg} / \mathrm{m}^{2}\right)$, a lower level of ATF was seen $(-15 \%, p=0.002)$. Other polymorphisms and phenotypes tested showed no association. Conclusion: A new +2138InsCAGACC MC3R polymorphism is associated with the level of adiposity and with body fat partitioning in interaction with corpulence in humans.

\section{Introduction}

The melanocortin system is implicated in the regulation of feeding behavior. For instance, mouse mutations such as lethal yellow $\left(\mathrm{A}^{\mathrm{Y}}\right)$ and viable yellow $\left(\mathrm{A}^{\mathrm{VY}}\right)$, cause the ubiquitous expression of the agouti protein, which appears to serve as an antagonist to melanocortin receptors (1-5). This results in an obesity syndrome associated with insulin resistance. The pro-opiomelanocortin (POMC) produces the alpha-

Address correspondence and reprint requests to: Yvon C. Chagnon, PhD, Genomic Laboratory, Genetic and Molecular Psychiatric Unit, Laval University Robert-Giffard Research Center, 2601, chemin de la Canardière, Room F.6423, Beauport (Québec), G1J 2G3 Canada. Phone: 418-663-5747 ext. 4717; fax: 418-663-8756; e-mail: yvon.chagnon@crulrg.ulaval.ca melanocyte-stimulating hormone ( $\alpha$-MSH), which is a natural agonist of the melanocortin receptors. It was shown that POMC-null mutant in mouse (6) and human POMC-deficient patients $(7,8)$ lacking $\alpha-\mathrm{MSH}$, also develop an obesity syndrome. Similarly, the knockout of the melanocortin 4 receptor (MC4R) gene in mice (9), and naturally occurring mutations in human (10-12) also induced obesity. We have also reported an association between MC4R and the body mass index (BMI) and fat mass in a normal population including all the range of BMI and fatness (13).

The melanocortin 3 receptor (MC3R) gene is intronless (14) and located on chromosome 20q13 (15). MC3R encodes a protein of 360 amino acids (16). Recently, the inactivation of MC3R in mice has been shown to not induce obesity, but an increase 
in the amount of adipose tissue at the expense of lean tissue mass was observed $(17,18)$. We have reported previously in human a weak linkage between body composition phenotype and a Pstl polymorphism in MC3R in the Québec Family Study (QFS) (19). On the other hand, in two different studies, no association was observed between polymorphisms within MC3R and obesity $(20,21)$.

To clarify the possible involvement of MC3R in body composition in humans, we have analyzed three polymorphisms related to MC3R gene and performed association studies with different body composition, energy intake, and energy expenditure of activity phenotypes. One insertion and one single nucleotide polymorphisms, the latter located within the coding region, and one microsatellite marker (22) were assayed in the QFS cohort.

\section{Materials and Methods}

\section{Subjects and Phenotypes}

The QFS cohort has been previously described (23). Blood samples were obtained for various biochemical assays and genomic DNA was prepared from permanent lymphoblastoid cells line by protein $\mathrm{K}$ and genomic-tips protocol (Qiagen, Santa Clara, CA, USA). Subjects 18 years and older were retained for the study. The following phenotypes were analyzed: BMI, sum of six skinfold thicknesses (SF6), and percent body fat (\%FAT) estimated from body density measurements obtained by underwater weighing (24) using the equation of Siri (25) with an estimation of the residual pulmonary volume (26). Fat mass (FM) and fat-free mass (FFM) were obtained from \%FAT and body weight. Respiratory quotient (RQ) and resting metabolic rate (RMR) were assessed early in the morning in a fasted state by indirect calorimetry over a 30 -min period using an open-circuit system with a ventilated hood. Data from the last 10-min have been used for the calculation of RMR and RQ (27). Plasma levels of insulin and leptin have been measured in the morning after a 12-hr overnight fast by radioimmunoassay. The lowest leptin quantity detectable was $0.5 \mathrm{ng} / \mathrm{ml}$ (LinCo, StCharles, MO, USA). Insulin was measured following polyethylene glycol precipitation (28). Computed tomography (CT) was performed on a Siemens Somatom DRH scanner (Erlangen, Germany) to quantify abdominal visceral, subcutaneous (ASF), and total (ATF) fat according to the methodology previously described (29). Energy intake (INT) was calculated from a 3-day dietary intake record (30), and energy expenditure of activity (EXP) from a 3-day physical activity diary (31).

\section{Genotyping}

Restriction Fragment Length Polymorphism (RFLP) V81I (G241A) Polymorphism. Conditions for the typing of the MC3R valine (V) to isoleucin (I) change at amino acid 81, arising from a guanine (G) to adenosine (A) substitution at position 241 (GTT to ATT) of the human MC3R gene (Genbank:
XM_009545) have been adapted from Li et al. (20). The G-to-A substitution removes a Bsajl restriction site at this position. DNA fragment was amplified by PCR using the forward primer tailed with a M13 sequence (in lowercase) 5'-cac gac gtt gta aaa cga CTG CTG CCT GCC CTC TGT T-3' and the reverse primer 5'-GCC AGG ATA ACC AGG ATG T-3'. The PCR was performed using $50 \mathrm{ng}$ genomic DNA, $0.4 \mu \mathrm{M}$ forward primer, $0.6 \mu \mathrm{M}$ reverse primer, $125 \mu \mathrm{M}$ of each dNTP (Pharmacia, Baie D'Urfe, Quebec, Canada), $1 \mu \mathrm{M}$ of M13 FW (-29)/ IRD 700 or 800 infrared tagged complementary primer (LiCor, Lincoln, NC, USA), and 0.3 U Taq DNA polymerase in PCR reaction buffer (Qiagen) in a final volume of $10 \mu$ l. Two-step PCR was carried out for 32 cycles, with 10 cycles of $30 \mathrm{sec}$ of denaturation at $94^{\circ} \mathrm{C}$ and $45 \mathrm{sec}$ of annealing at $55^{\circ} \mathrm{C}$, and 22 cycles of $30 \mathrm{sec}$ of denaturation at $94^{\circ} \mathrm{C}, 45 \mathrm{sec}$ of annealing at $52^{\circ} \mathrm{C}$ and an extension of $10 \mathrm{sec}$ at $72^{\circ} \mathrm{C}$ (Perkin Elmer 9600, Foster City, CA, USA). PCR products were digested overnight at $50^{\circ} \mathrm{C}$ with $0.75 \mathrm{U}$ of BsaJl (New England Biolabs, Mississauga, Ontario, Canada), and DNA fragments separated on denaturing $5.5 \%$ acrylamide gels using automatic DNA sequencer (Model 4200, LiCor). For the I81 allele, a DNA fragment of $174 \mathrm{bp}$ is detected, and for the V81 allele a fragment of $119 \mathrm{bp}$ with an undetected $55 \mathrm{bp}$ fragment.

+2138InsCAGACC polymorphism. The +2138InsCAGACC polymorphism, originally a Pstl RFLP (19), was detected by Southern blot analysis. To the 535 subjects originally genotyped (19), 200 more were added. Genomic DNA (1 $\mu \mathrm{g})$ was digested overnight at $37^{\circ} \mathrm{C}$ with $5 \mathrm{U}$ of Pstl (New England Biolabs). The DNA fragments were separated on a $1 \%$ agarose gel by electrophoresis in IX TAE $(40 \mathrm{mM}$ Tris-acetate, $1 \mathrm{mM}$ EDTA, pH 8.0) and transferred by alkali blotting (0.25 $\mathrm{M} \mathrm{NaOH}, 1.5 \mathrm{M} \mathrm{NaCl}$ ) to nylon membrane (Hybond $\mathrm{N}^{+}$, Amersham, Piscataway, NJ, USA). The DNA of the Southern blot was hybridized with a probe including the complete MC3R coding sequence. The probe was labeled with $\alpha-\left[{ }^{32} \mathrm{P}\right]$ dCTP by random priming (Multiprime DNA labeling systems, Amersham, Piscataway, NJ, USA) with a specific activity up to $2 \times 10^{9} \mathrm{cpm} / \mathrm{ug}$. Hybridizations were carried out at $65^{\circ} \mathrm{C}$ overnight in hybridization oven (Robbins Scientific Corporation, Sunnyvale, CA, USA) using hybridization solution $\left(\mathrm{Na}_{2} \mathrm{HPO}_{4} 0.25 \mathrm{M}, \mathrm{pH}\right.$ 7.4; EDTA $1 \mathrm{mM}$, pH 8.0; SDS $7 \%$ ) containing $60 \mu \mathrm{g} / \mathrm{ml}$ of sonicated salmon sperm DNA (Stratagene, Cedar Greek, TX, USA), and $10^{6} \mathrm{cpm} / \mathrm{ul}$ of heat denatured probe. The blot was previously prehybridized $60 \mathrm{~min}$ in the same solution without the probe. Autoradiography was performed using Kodak XAR-5 film with intensifying screens for $5-7$ days at $-80^{\circ} \mathrm{C}$. The size of the fragments was estimated using lambda Hind III/Eco RI fragment length standards. The Pst 1 RFLP showed two alleles of 4.4 and $3.6 \mathrm{~kb}$, and a constant band of $900 \mathrm{bp}$.

To localize the polymorphic Pstl site, we tested a putative site located between nucleotide $+\mathbf{2 5 4 6}$ and +3249 reported from the Human Genome Sequencing 
Project, and the region between nucleotide +1720 and +2846. PCR was performed using, respectively, primers 5'-AGGAACCTTTGAACTGGGAC-' 3 and 5'-GGTAATGGGAGACACTGAAGAG, and primers 5'-CCGCTCAGTGGGTAAATGTAG-' 3 and 5'-TGAGAATCTGAGAAAGTGGTCG, 50 ng genomic DNA of each two wild-type and two variant homozygotes for the Pstl site, $125 \mu \mathrm{M}$ of each dNTP (Pharmacia), and $0.3 \mathrm{U}$ Taq DNA polymerase in PCR reaction buffer (Qiagen) in a final volume of $10 \mu \mathrm{l}$. PCR was carried out for 35 cycles, $30 \mathrm{sec}$ of denaturation at $94^{\circ} \mathrm{C}, 45 \mathrm{sec}$ of annealing at $60^{\circ} \mathrm{C}$, and an extension of $10 \mathrm{sec}$ at $72^{\circ} \mathrm{C}$ (Perkin Elmer 9600). PCR products were digested overnight at $37^{\circ} \mathrm{C}$ with $1 \mathrm{U}$ of Pst 1 (New England Biolabs), and DNA fragments were separated on $2.0 \%$ agarose gel electrophoresis.

Microsatellite D20S32e. The D20S32e TG dinucleotide repeat microsatellite marker, located $5^{\prime}$ to MC3R between nucleotides -1933 and -1892 , has been assayed as described previously (22) except that an M13 tail was added to the forward primer and an M13 tagged complementary primer was used to detect PCR products using automatic DNA sequencer (LiCor). Genotypes were imported electronically directly in a local database (GENEMARK) in which a procedure to check for Mendelian inheritance incompatibilities within families has been implemented. Subjects displaying Mendelian incompatibilities were reassayed completely (from the PCR to the genotyping). The microsatellite D20S32e exhibited alleles of 115, 117, 119, 121, and $123 \mathrm{bp}$.

DNA Sequencing. To confirm the variations observed for the V81I polymorphism, one subject homozygote for either of the two alleles and one heterozygote subject were sequenced. The sequence was performed using DNA sequence kit-LC (SequiThern Excel II, Epicentre Technologies, Madison, WI, USA) according to the protocol and visualized on the automatic DNA sequencer (LiCor). Similarly, to confirm the location of the Pstl polymorphic site, one homozygote subject for each of the alleles were sequenced for all the coding region, and for a targeted region between nucleotides +1720 and +2846 on an ABI 377 Stretch DNA sequencer.

\section{Statistical Analysis}

Phenotype differences across genotypes were tested including all subjects from families using a covariance analysis with age, age $^{2}$, and sex as covariates, plus BMI for RQ, RMR, INT and EXP, or plus SF6 for ATF, ASF, log insulin, and leptin. For covariance analysis, because we included related subjects, we used the SAS procedure mixed association analysis to adjust for non-independence in family data. The SAS package (version 8) for PC was used for the analysis. Probability values $(p)$ were adjusted for multiple testing using the Bonferroni correction in which the adjusted $p$ value $p^{*}=1-(1-p)^{\text {number of traits. }}$
Subjects for D20S32e were grouped as follows: $119 / 119 \mathrm{bp}$ homozygotes, $119 \mathrm{bp} /$ other allele heterozygotes, and other genotypes. In the case of the V81I polymorphism, carriers of the I81 variant allele (V81I and I81I subjects) and noncarriers (V81V homozygotes) were compared. Linkage disequilibrium between polymorphisms was estimated using EH program (J. Ott, Rockefeller University, New York, October 1997).

\section{Results}

We studied three MC3R polymorphisms. For the Pstl polymorphism, the Southern blot showed two alleles with length estimated at 4.4 and $3.6 \mathrm{~kb}$ for the wild-type and variant alleles, respectively (Fig. 1), with a constant band at 900 bp (data not shown). We have located the Pstl polymorphic site at nucleotide +2138 where we observed an insertion of six nucleotides (+2138InsCAGACC), the last C creating the new Pstl (CTGCAG) polymorphic site. This corresponds, according to the Human Genome Sequence, to Pst l DNA fragments of 3.7 and $3.0 \mathrm{~kb}$, with the 900-bp constant fragment arising from the internal MC3R Pstl site located at nucleotide 345 (Fig. 2). Sequencing of the complete MC3R coding region does not reveal any additional Pst 1 site.

The V81I polymorphism detected by BsaJl is located at nucleotide 241 within codon 81 of MC3R gene. In contrast to a previous report (20), we found that the V81 allele was the most frequent allele in our Caucasian population. We confirmed the genotypes by sequencing PCR amplified fragment from V81V and I81I homozygote and V81I heterozygote subjects (Fig. 3). The microsatellite D20S32e, which is located between nucleotide -1933 and -1892 , exhibited alleles of 115, 117, 119, 121, and $123 \mathrm{bp}$. The observed genotype and allele frequencies for these three polymorphisms in QFS are shown in Table 1. HardyWeinberg equilibrium was observed for all three polymorphisms $(+2138$ InsCAGACC, $p=0.78$; V81I, $p=0.68$; and D20S32e, $p=0.78$ ), whereas a small linkage disequilibrium (LD) is observed between

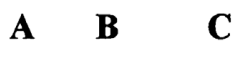

$4.4 \mathrm{~kb}$

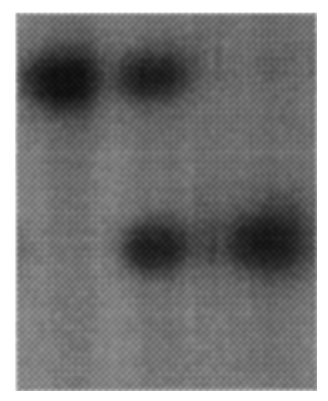

Fig. 1. Original RFLP banding pattern of MC3R restricted with (A) wild-type homozygote, (B) heterozygote, and (C) variant homozygote. 

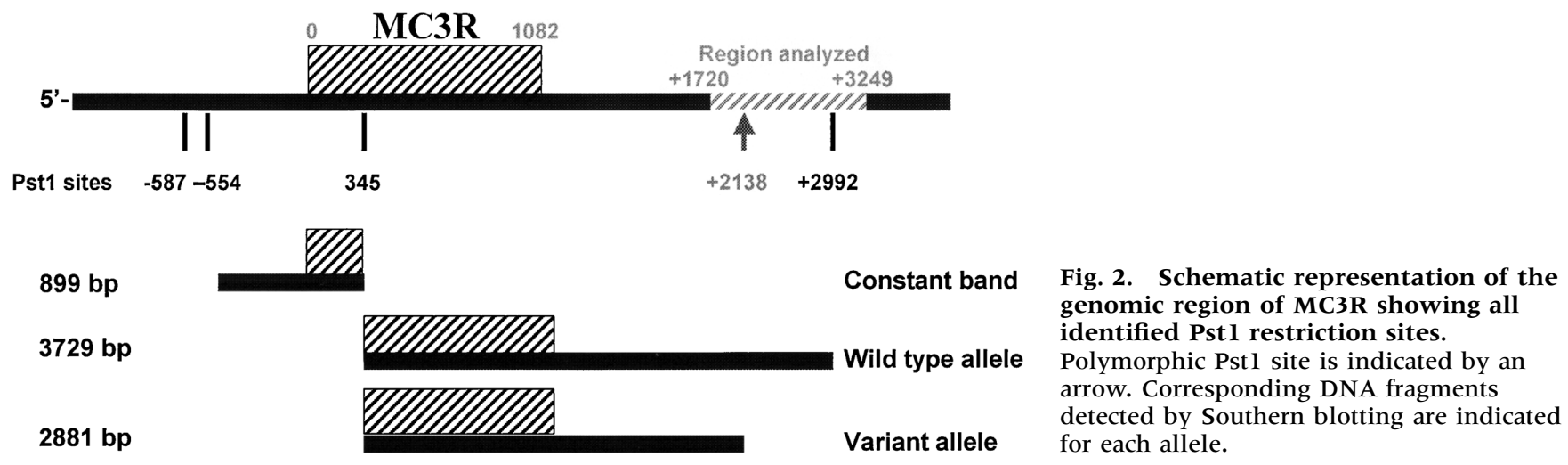

+2138 InsCAGACC and V81I $(p=0.007)$, but not with D20S32e $(p=0.110)$. V81I and D20S32e showed also a weak LD $(p=0.016)$.

QFS represents an overweight cohort (mean BMI of $27.3 \pm 7.5$ ) including lean (minimum BMI of 14) and obese (maximum BMI of 65) subjects. Accordingly, \%FAT ranged from $2.9-59.8 \%$ (mean of $27.7 \pm 10.8 \%$ ). Mean age is $40.8 \pm 17.7$ years (range, 10-93.5), with only subjects over 18 years included in the analysis, and a proportion of $56 \%$

\section{C $\quad \mathbf{G} \quad \mathbf{T} \quad \mathbf{A}$}

A)

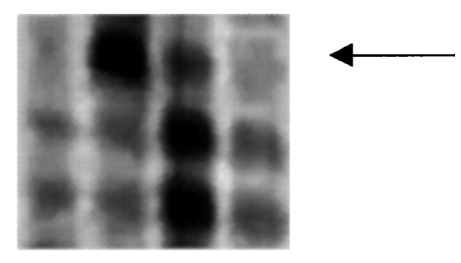

B)

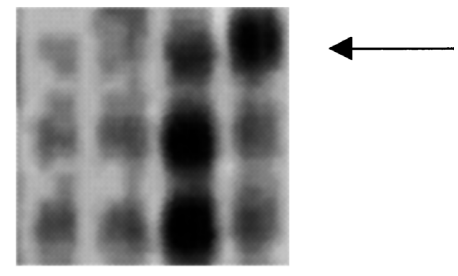

C)

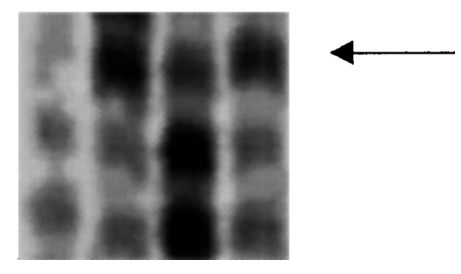

Fig. 3. DNA sequence of the V81I polymorphism at nucleotide 241 of MC3R for members of the same family. (A) Father (G241/G241). (B) Mother (A241/A241). (C) Offspring (G241/A241). Arrow indicated position of nucleotide 241. females. Associations between the +2138InsCAGACC polymorphism and body composition-related phenotypes were observed when the data were analyzed by BMI categories (Table 2). Associations were observed in normal weight subjects $($ BMI $<25$ $\mathrm{kg} / \mathrm{m}^{2}$ ) with \%FAT and FM (Table 2), which remained significant after a Bonferroni correction for multiple testing $(p=0.008$ and $p=0.005)$. Homozygote subjects for the +2138 insertion allele showed higher mean values than the heterozygotes and the wild-type homozygotes $(+4 \% \%$ FAT and $+3 \mathrm{~kg}$ to $+4 \mathrm{~kg} \mathrm{FM})$. Associations $(0.0001 \leq p \leq$ $0.03)$ was also observed in overweight subjects $\left(25 \leq \mathrm{BMI}<30 \mathrm{~kg} / \mathrm{m}^{2}\right)$ with BMI, \%FAT, FM, RQ, and INT (Table 2), but where \%FAT and FM only remained significant after Bonferroni correction ( $p=0.03$ and $p=0.002)$. For these phenotypes, homozygote subjects for the +2138 insertion allele had lower mean values $(-4 \% \% \mathrm{FAT},-4$ to $-5 \mathrm{~kg}$ FM) than the heterozygotes and the wild-type homozygotes. Thereafter, despite differences in BMI between normal weight and overweight subjects, the +2138 insertion homozygote subjects showed close mean values of \%FAT and FM in contrast to other genotypes $( \pm 3 \% \%$ FAT and $\pm 2 \mathrm{~kg}$ FM for +2138 insertion homozygotes versus $\pm 10-12 \%$ $\%$ FAT and $\pm 9-11 \mathrm{~kg}$ FM for the other genotypes). Nonsignificant lower values of \%FAT and FM for the +2138 insertion homozygote genotype were also observed among obese subjects (BMI $\geq$ $30 \mathrm{~kg} / \mathrm{m}^{2} ;-3 \% \%$ FAT, -4 to $-5 \mathrm{~kg}$ FM; $p>0.35$; Table 2). However, the obese subjects showed associations with ASF and ATF (Table 2), ATF remaining significant after Bonferroni correction $(p=0.03)$. Homozygotes for the +2138 insertion allele showed lower mean values $(-14$ to $-16 \%)$ than the heterozygotes and wild-type homozygotes. In addition to phenotypes presented in Table 2, we also analyzed the insulin level (pmol/L), leptin (ng/ml), RMR, EXP, FFM, SF6, and height, and no significant association between +2138InsCAGACC MC3R polymorphism and those phenotypes was observed. Similarly, no relation between D20S32e and V81I polymorphisms and any of the phenotypes were uncovered (data not shown). 
Table 1. Allele and genotype frequencies in unrelated subjects for the different polymorphisms of MC3R gene in QFS

\begin{tabular}{|c|c|c|c|c|c|c|}
\hline \multirow[b]{2}{*}{ Polymorphisms } & \multirow[b]{2}{*}{ Genotypes } & \multicolumn{2}{|c|}{ Frequency } & \multirow[b]{2}{*}{ Alleles } & \multicolumn{2}{|c|}{ Frequency } \\
\hline & & $\%$ & $N$ & & $\%$ & $N$ \\
\hline \multirow[t]{3}{*}{ +2138InsCAGACC } & wt/wt & 56.5 & 183 & wt & 75.9 & 492 \\
\hline & wt/Ins & 38.9 & 126 & Ins & 24.1 & 156 \\
\hline & Ins/Ins & 4.6 & 15 & & & \\
\hline \multirow[t]{3}{*}{ V81I (G241A) } & V81/V81 & 79.3 & 176 & V81 & 89.2 & 396 \\
\hline & V81/I81 & 19.8 & 44 & I81 & 10.8 & 48 \\
\hline & I81/I81 & 0.9 & 2 & & & \\
\hline \multirow[t]{11}{*}{ D20S32e } & $115 / 119$ & 1.5 & 5 & 115 & 0.7 & 5 \\
\hline & $117 / 117$ & 0.2 & 1 & 117 & 9.8 & 67 \\
\hline & $117 / 119$ & 14.9 & 51 & 119 & 68.7 & 471 \\
\hline & $117 / 121$ & 2.6 & 9 & 121 & 13.1 & 90 \\
\hline & $117 / 123$ & 1.5 & 5 & 123 & 7.7 & 53 \\
\hline & $119 / 119$ & 45.2 & 155 & & & \\
\hline & $119 / 121$ & 19.0 & 65 & & & \\
\hline & $119 / 123$ & 11.7 & 40 & & & \\
\hline & $121 / 121$ & 1.7 & 6 & & & \\
\hline & $121 / 123$ & 1.2 & 4 & & & \\
\hline & $123 / 123$ & 0.6 & 2 & & & \\
\hline
\end{tabular}

Abbreviations: Ins, Insertion; wt, wild-type.

\section{Discussion}

We observed a significant association between the +2138InsCAGACC MC3R polymorphism and body fatness in QFS (Table 2). These results are in line with those of Lembertas et al. study (19), which revealed weak linkages between +2138InsCAGACC polymorphism, reported previously as a Pst 1 RFLP (19), and BMI and FM in the same QFS cohort. However, an association with fasting insulin was not observed, in contrast to the reported linkage (19). These associations were observed within BMI classes only, which indicate an interaction with body corpulence. The +2138 insertion homozygote subjects with normal weight have higher \%FAT and FM than those of other genotypes in this BMI category. Incidentally, those subjects have an overall increased adiposity, while keeping a similar BMI. A similar phenotype was observed in MC3R knockout mice $(17,18)$ but, in contrast to our results, the knockout mice showed a lower lean body mass that is not apparent in QFS subjects. On the other hand, despite a higher BMI, the overweight +2138 insertion variant homozygotes have \%FAT and FM similar to normal weight subjects, but with a slightly higher energy intake than other genotypes. Hence, the +2138 insertion variant homozygotes better control their fatness in spite of a higher energy intake.

Abdominal fat in normal weight and overweight subjects carrying the +2138 insertion variant genotype was similar to other genotypes, whereas in the obese subjects the +2138 insertion variant homozygotes showed less abdominal fat, particularly subcutaneous in contrast to visceral fat, than other genotypes. These results showed that the +2138 insertion homozygotes controlled better their fatness than subjects of other genotypes, and that this genotype could be involved in body fat partitioning according to corpulence with obese subjects showing less abdominal fat than nonobese subjects for the +2138 insertion variant genotype. To confirm these results, it would be of interest to compare level of expression and/or activity of MC3R in fat from obese and nonobese subjects homozygote for the +2138 insertion variant allele versus those carrying the +2138 wild-type allele. Alternatively, in vitro expression of the two forms of the receptor could provide information on their biological effects.

The V81I polymorphism is located within the MC3R gene at codon 81 (Val $\rightarrow$ Ile, GTT $\rightarrow$ ATT). This region is conserved and encodes the first transmembrane domain of MC3R protein. An amino acid change at this position could have functional implications. However, we did not find any association between this polymorphism and the body composition, energy, and glucose metabolism phenotypes. These results are in line with those of Li et al. (20), which did not show any association between V81I and BMI in extremely obese Caucasian women $\left(\mathrm{BMI}>40 \mathrm{~kg} / \mathrm{m}^{2}\right)$. They also support results of Hani et al. (21), which did not show any association 


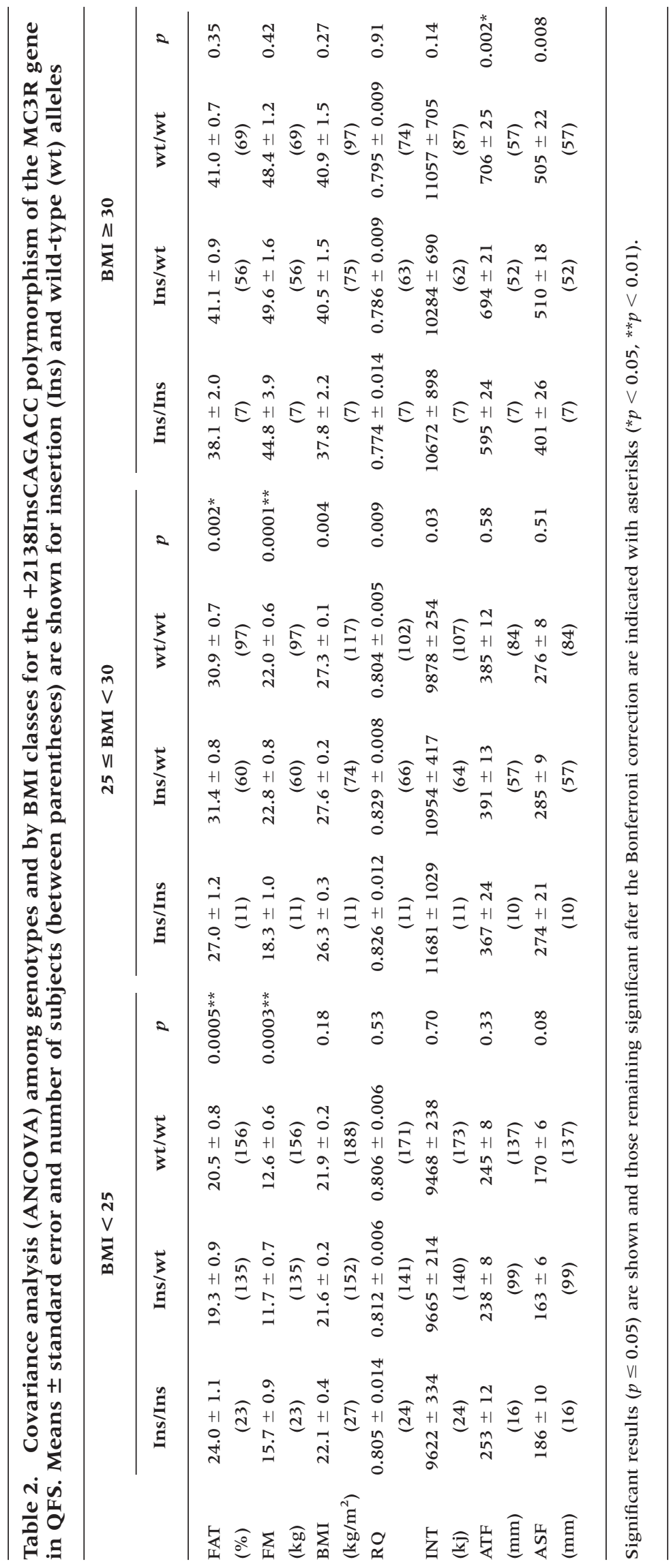


between V81I polymorphism and obesity or diabetes in French families with type 2 diabetes mellitus. However, we observed in QFS 80.6\% homozygote $(\mathrm{V} 81 \mathrm{~V}), 18.8 \%$ heterozygote (V81I), and $0.6 \%$ homozygote (I81I), in contrast to Li et al., who reported no homozygote (V81V), 11\% heterozygotes (V81I), and 89\% homozygote (I81I) in extremely obese Caucasian women (20). We sequenced the PCR fragment from members of the same family with the three genotypes to confirm our genotyping results. Our results indicate that the wild-type sequence is GTT (Val) and the variant sequence is ATT (Ile) (Fig. 3). Recently, the National Center for Biotechnology submitted a MC3R sequence (Genbank: XM_009545) with a wild-type sequence GTT (Val). Moreover, in rat (Genbank: X70667) (32), mice (Genbank: NM_008561) (33) and chicken (Genbank: AB017137) (34), the wild-type sequence is also GTT (Val). Additionally, frequencies reported in the paper of Hani et al. (21) were similar to those observed in the actual study. We also did not find any association between the microsatellite marker D20S32e and the same phenotypes. The analyses revealed five alleles in contrast to six alleles in the Yamada study, but the 119 allele was the more frequent one in both studies (22).

In conclusion, the +2138 insertion variant genotype of MC3R maintained level of fat similar in normal weight and overweight subjects, while distribution of abdominal fat was the same for all three genotypes. In obese subjects, although the mechanism of control of the overall level of fat appears to be overridden, the variant subjects showed less abdominal subcutaneous fat than other genotypes. These results support the hypothesis that MC3R could be implicated in the regulation and the distribution of adiposity in human.

\section{Acknowledgments}

The authors want to acknowledge the contribution of Michel Lacaille and Chantal Paré for laboratory work, Claude Leblanc for statistical analysis support, Christian Couture for computer and software assistance, and Dr. William $\mathrm{O}$. Wilkison for the MC3R probe. Thanks are also expressed to Guy Fournier and Lucie Allard for their contribution to the data collection of this study. This work was supported by the Canadian Institutes of Health Research (C.I.H.R.) (MT-13960).

\section{References}

1. Bultman SJ, Michaud EJ, Woychik RP. (1992) Molecular characterization of the mouse agouti locus. Cell 71: 11951204.

2. Michaud EJ, Bultman SJ, Stubbs LJ, et al. (1993) The embryonic lethality of homozygous lethal yellow mice (Ay/Ay) is associated with the disruption of a novel RNA-binding protein. Genes Dev. 7: 1203-1213.

3. Michaud EJ, van Vugt MJ, Bultman SJ, et al. (1994) Differential expression of a new dominant agouti allele (Aiapy) is correlated with methylation state and is influenced by parental lineage. Genes Dev. 8: 1463-1472.

4. Duhl DM, Vrieling H, Miller KA, et al. (1994) Neomorphic agouti mutations in obese yellow mice. Nat Genet. 8: 59-65.

5. Duhl DM, Stevens ME, Vrieling H, et al. (1994) Pleiotropic effects of the mouse lethal yellow (Ay) mutation explained by deletion of a maternally expressed gene and the simultaneous production of agouti fusion RNAs. Development 120: 1695-1708.

6. Yaswen L, Diehl N, Brennan MB, et al. (1999) Obesity in the mouse model of pro-opiomelanocortin deficiency responds to peripheral melanocortin. Nat. Med. 5: 1066-1070.

7. Krude H, Biebermann H, Luck W, et al. (1998) Severe earlyonset obesity, adrenal insufficiency and red hair pigmentation caused by POMC mutations in humans. Nat. Genet. 19: 155-157.

8. Krude H, Gruters A. (2000) Implications of proopiomelanocortin (POMC) mutations in humans: The POMC deficiency syndrome. Trends Endocrinol. Metab. 11: 15-22.

9. Huszar D, Lynch CA, Fairchild-Huntress V, et al. (1997) Targeted disruption of the melanocortin-4 receptor results in obesity in mice. Cell 88: 131-141.

10. Vaisse C, Clement K, Guy-Grand B, et al. (1998) A frameshift mutation in human MC4R is associated with a dominant form of obesity. Nat. Genet. 20: 113-114.

11. Yeo GS, Farooqi IS, Aminian S, et al. (1998) A frameshift mutation in MC4R associated with dominantly inherited human obesity. Nat. Genet. 20: 111-112.

12. Hinney A, Schmidt A, Nottebom K, et al. (1999) Several mutations in the melanocortin-4 receptor gene including a nonsense and a frameshift mutation associated with dominantly inherited obesity in humans. J. Clin. Endocrinol. Metab. 84: 1483-1486.

13. Chagnon YC, Chen WJ, Pérusse L, et al. (1997) Linkage and association studies between the melanocortin receptors 4 and 5 genes and obesity-related phenotypes in the Quebec Family Study. Mol. Med. 3: 663-673.

14. Schioth HB, Muceniece R, Wikberg JE, et al. (1996) Alternative translation initiation codon for the human melanocortin MC3 receptor does not affect the ligand binding. Eur. J. Pharmacol. 314: 381-384.

15. Gantz I, Tashiro T, Barcroft C, et al. (1993) Localization of the genes encoding the melanocortin-2 (adrenocorticotropic hormone) and melanocortin-3 receptors to chromosomes $18 \mathrm{p} 11.2$ and 20q13.2-q13.3 by fluorescence in situ hybridization. Genomics 18: 166-167.

16. Gantz I, Konda Y, Tashiro T, et al. (1993) Molecular cloning of a novel melanocortin receptor. J. Biol. Chem. 268: 8246-8250.

17. Chen AS, Marsh DJ, Trumbauer ME, et al. (2000) Inactivation of the mouse melanocortin-3 receptor results in increased fat mass and reduced lean body mass. Nat. Genet. 26: 97-102.

18. Butler AA, Kesterson RA, Khong K, et al. (2000) A unique metabolic syndrome causes obesity in the melanocortin-3 receptor-deficient mouse. Endocrinology 141: 3518-3521.

19. Lembertas AV, Pérusse L, Chagnon YC, et al. (1997) Identification of an obesity quantitative trait locus on mouse chromosome 2 and evidence of linkage to body fat and insulin on the human homologous region 20q. J. Clin. Invest. 100: 1240-1247.

20. Li W, Joo E, Furlong E, et al. (2000) Melanocortin 3 receptor (MC3R) gene variants in extremely obese women. Int. J. Obes. 24: 206-210.

21. Hani EH, Dupont S, Durand E, et al. (2001) Naturally occurring mutations in the melanocortin receptor 3 gene are not associated with type 2 diabetes mellitus in French Caucasians. J. Clin. Endocrinol. Metab. 86: 2895-2898.

22. Yamada Y, Xiang KS, Bell GI, et al. (1991) Dinucleotide repeat polymorphism in a gene on chromosome 20 encoding a Gprotein coupled receptor (D20S32e). Nucleic Acids Res. 19: 2519.

23. Bouchard C. (1996) Genetic epidemiology, association and sib-pair linkage: Results from the Quebec Family Study. In Molecular and Genetic Aspects of Obesity. Baton Rouge: Louisiana State University Press; 470-481.

24. Behnke A, Wilmore J. (1974) Evaluation and regulation of body build and composition. Englewood Cliffs, NJ: PrenticeHall; 236. 
25. Siri WE. (1976) The gross composition of the body. In Lawrence JH (ed). Advances in Biological and Medical Physics. New York: Academic Press; 239-280.

26. Himes JH, Bouchard C. (1989) Validity of anthropometry in classifying youths as obese. Int. J. Obes. 13: 183-193.

27. Deriaz O, Dionne F, Pérusse L, et al. (1994) DNA variation in the genes of the $\mathrm{Na}, \mathrm{K}$-adenosine triphosphatase and its relation with resting metabolic rate, respiratory quotient, and body fat. J. Clin. Invest. 93: 838-843.

28. Desbuquois B, Aurbach GD. (1971) Use of polyethylene glycol to separate free and antibody-bound peptide hormones in radioimmunoassays. J. Clin. Endocrinol. Metab. 33: $732-738$.

29. Ferland M, Després JP, Tremblay A, et al. (1989) Assessment of adipose tissue distribution by computed axial tomography in obese women: association with body density and anthropometric measurements. Br. J. Nutr. 61: 139-148.
30. Tremblay A, Sévigny M, Leblanc C, et al. (1983) The reproducibility of a tree-day dietary record. Nutrition Research 3: 819-830.

31. Bouchard C, Tremblay A, Leblanc C, et al. (1983) A method to assess energy expenditure in children and adults. Am. J. Clin. Nutr. 37: 461-467.

32. Roselli-Rehfuss L, Mountjoy KG, Robbins LS, et al. (1993) Identification of a receptor for gamma melanotropin and other proopiomelanocortin peptides in the hypothalamus and limbic system. Proc. Natl. Acad. Sci. U.S.A. 90: 8856-8860.

33. Desarnaud F, Labbe O, Eggerickx D, et al. (1994) Molecular cloning, functional expression and pharmacological characterization of a mouse melanocortin receptor gene. Biochem. J. 299: $367-373$.

34. Takeuchi S, Takahashi S. (1999) A possible involvement of melanocortin 3 receptor in the regulation of adrenal gland function in the chicken. Biochim. Biophys. Acta. 1448: 512-518. 